\title{
Performance and Emissions Characteristics of Diesel Engine Using Blends of Biodiesel from Jatropha Curcas L.
}

\author{
Muhammad Alam Zaib Khan ${ }^{* 1}$, Muhammad Ali Kamran*2, \\ Zuhaib Ali Khan ${ }^{* 3}$, Usman Ghani*4, Tufail Habib*5 \\ \#1-4 Department of Mechanical Engineering, \\ University of Engineering and Technology, Peshawar, Pakistan \\ \#5 Department of Industrial Engineering, \\ University of Engineering and Technology, Jalozai Campus, Pakistan \\ 1 alamzaibkhan@uetpeshawar.edu.pk
}

\begin{abstract}
The known reserves of fossil fuels of our world are depleting at faster rate. Our vehicles run on fossil fuels and with the depletion, we are facing an imminent threat. This calls for research in alternative fuels. This current research has been done in biodiesel from Jatropha seeds. Biodiesel extracted from Jatropha is an ideal alternative fuel for several reasons; it has a higher Cetane number of 51 as compared to other oils and which is near to that of Diesel whose Cetane number lied in the range of 46-50. Therefore, it has desired physical and chemical properties and performance parameters like those of conventional diesel which is a reason why it does not require any modifications in diesel engine to a certain mix ratio. This paper deals with the utilization of two blends of Biodiesel mixed in conventional diesel using a four stoke diesel engine with engine working at different speeds and varying loads. Performance and exhaust emissions variation were determined for the engine for conventional diesel fuel and compared with the two bio-diesels blends. Theoretical characteristics of diesel engine combustion with the different physiochemical properties of these two blends, helps to correctly interpret the observed engine behaviour.
\end{abstract}

Keyword - Jatropha, Biodiesel, Biodiesel blending, Diesel Engine Performance.

\section{INTRODUCTION}

There has been energy crisis throughout the World due to depletion of fossil fuel. Due to limited reservoir of fossil sources, research trend has shifted towards alternative and renewable energy [1]. Fossil resources like petroleum, natural gas and coal, are highly depleting. Due to limited reservoir of fossil sources, many researchers are looking for alternative fuels which can be produced from renewable resources. Biodiesel is one of the renewable energy resources which is eco-friendly and that is why more striking to the researchers [2].

Jatropha curcas L oil is gaining popularity among many researchers as the raw material for biodiesel production because it is nonedible and unsafe for human consumption due to presence of toxic compounds [3]. The oil content of Jatropha curcas L. seed is very high and its properties are similar to conventional diesel [4]. Biodiesel production is affected by many dynamics that include catalyst concentration, molar ratios of alcohol to oil, reaction time and reaction temperature. Biodiesel Oils/fats are basically triglycerides having three long-chain fatty acids. They have high viscosity than conventional diesel and therefore cannot be used as a fuel [4]. These triglycerides are first converted into esters by a process known as transesterification reaction in order to reduce viscosity this process gives Glycerin as a byproduct while the esters are known as biodiesel [5].

During combustion the biodiesel, although it produces pollutants, produces lesser amount of pollutants as compared to petro-diesel [6]. Due to high viscosity, this Biodiesel cannot directly be used as a fuel in compression engines due to poor atomization which results in carbon deposition caused by incomplete combustion and eventual engine failures [4]. Low volatility and polyunsaturated character are some other limitations of direct usage of vegetable oil as fuel [4]. These problems can be overcome by deploying processes like pyrolysis, microemulsification, transesterification, etc [4]. Although Pyrolysis has yielded some positive results like low viscosity, high cetane number, acceptable quantity of Sulfur, water, sediments and copper corrosion values, this method has been rejected because of its high ash content, carbon residues and pour point. On the other hand, transesterification, which converts triglycerides into glycerol and three molecules of esters, has been adopted as the most feasible method for lowering viscosity.

However, a general upward trend has been recorded in using $2^{\text {nd }}$ generation biofuels like Jatropha Biodiesel with high $(27 \%-45 \%)$ but toxic oil content. The toxicity is the major reason why it is not suitable for human consumption and thus will not pressurize the food industry [7]. 
Table I : Comparison of fuel properties $[8,9]$

\begin{tabular}{|l|l|l|}
\hline Fuel Property & Diesel & Jatropha Carcas L. \\
\hline Fuel Composition & $\mathrm{C}_{10}-\mathrm{C}_{21} \mathrm{HC}$ & $\mathrm{C}_{12}-\mathrm{C}_{22}$ FAME \\
\hline Density $@ 15^{\circ} \mathrm{C}, \mathrm{g} / \mathrm{ml}$ & 0.848 & 0.8826 \\
\hline Kinematic Viscosity at $40^{\circ} \mathrm{C} \mathrm{mm} / \mathrm{s}$ & $1.3-4.1$ & 4.016 \\
\hline Flash Point $\left({ }^{\circ} \mathrm{C}\right)$ & $60-80$ & 117 \\
\hline Calorific Value $(\mathrm{MJ} / \mathrm{kg})$ & 45.5 & 41.72 \\
\hline
\end{tabular}

Jatropha oil has lower calorific value, in contrast conventional diesel whose calorific value is about $45 \mathrm{MJ} / \mathrm{kg}$, while Jatropha biodiesel has a heating value that lies in the range of $39-40 \mathrm{MJ} / \mathrm{kg}$. This is due to bonding of oxygen with triglycerides in vegetable oils resulting in lowering the heating value by about $10 \%$ [10].

\section{EXPERIMENTAL SETUP}

The experiment was carried out on a single cylinder, constant speed, direct combustion chamber diesel engine. The specification of the engine is given in Table II

Table II : Diesel Engine Specifications

\begin{tabular}{|l|l|}
\hline Ignition type & CI (4-stroke) \\
\hline Combustion System & Direct Combustion Chamber \\
\hline No of cylinder & Single \\
\hline Compression Ratio & $18 \pm 1$ \\
\hline Rated Speed (r/min) & 2400 \\
\hline Rated Power (KW) & $10(7.35 \mathrm{~kW})$ \\
\hline Specific Fuel Consumption $(\mathrm{g} / \mathrm{kW} \cdot \mathrm{h})$ & $\leq 283$ \\
\hline Bore x Stroke (mm) & $90 \times 90$ \\
\hline Displacement (L) & 0.573 \\
\hline
\end{tabular}

The engine was directly coupled to an Eddy Current Air-Cooled Engine dynamometer (DYNO-mite) which has a maximum load capacity of $20 \mathrm{hp}$. A load control unit is used to apply different loads using different current amperes. The fuel consumption rates were measured for different loads and fuel blends, along with the $\mathrm{CO}, \mathrm{HC}$ and NOx emissions that were measured with a CRYPTON gas analyzer. An S-beam load cell is used with the dynamometer to measure the torque of the engine. The data was recoded and plotted against 3 different torques of the diesel engine. The torque was measured via dynamometer using DYNOMAX 2000 software and an optical tachometer was used to find RPM of the engine. The schematic diagram of the experimental setup is showed in figure 1 .

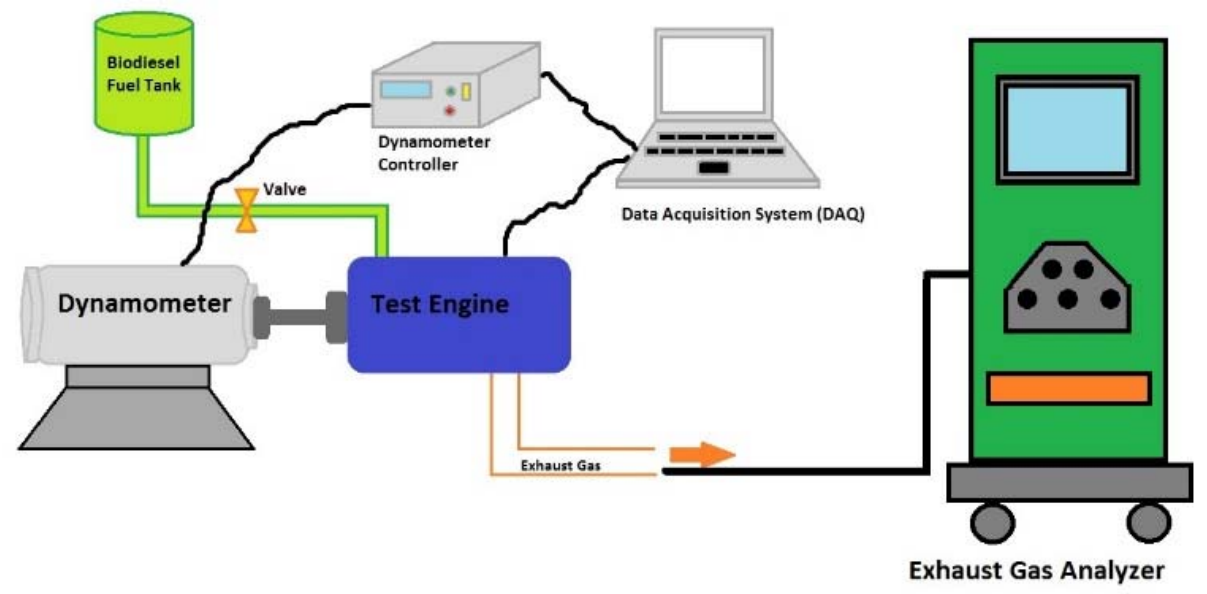

Figure 1 Experimental Setup 


\section{EXPERIMENTAL PROCEDURE}

A number of experiments were conducted to assess the performance and exhaust levels of Jatropha (biodiesels), of different blends B20 and B40, with the engine running at speeds from 1085 to $2400 \mathrm{rpm}$, and at three loads of $20 \%, 40 \%$ and $60 \%$ of the full load. Exhaust and performance parameters for engine running on conventional diesel is recorded first. The differences are compared with performance and exhaust emission parameters for engine that ran on diesel engine with two different blends of biodiesel from Jatropha separately.

In each test, exhaust smoke opaqueness and emissions of carbon monoxides and dioxide $\left(\mathrm{CO}_{\mathrm{x}}\right)$, and total unburned hydrocarbons $(\mathrm{HC})$ were measured. The experimental work was initiated with a prior investigation of compression ignition (CI) engine running on conventional Petro-diesel fuel to define the engine's datum operational physiognomies and emission levels. The tests were then repeated for B20 and B40 fuel blends at similar operating conditions. For every blend, the fuel lines were cleansed and rinsed thoroughly, and the engine was left to run idle for some time to adjust to the new conditions. Difference in the performance parameters from these two blends were compared with standard operation of the engine.

Since demonstration of the variation in the equivalence ratio (under load) for different blends is practically unfeasible and unrealistic because of the uncertainties related to air measurement and unknown chemical composition of the blends, it is therefore avoided.

\section{RESUlTS AND DISCUSSION}

The variations of different performance and emission characteristics parameters with torque are presented graphically in this section.

\section{a. ENGINE EMISSIONS}

Figure 2 shows how the number of hydrocarbons (HC) increases with increasing load for each type of fuel. Also the $\mathrm{HC}$ quantity decreases as the percentage of biodiesel increases in fuel i.e. $\mathrm{HC}$ for diesel is more than $\mathrm{B} 20$ at different loads and B20 is having more $\mathrm{HC}$ than B40.

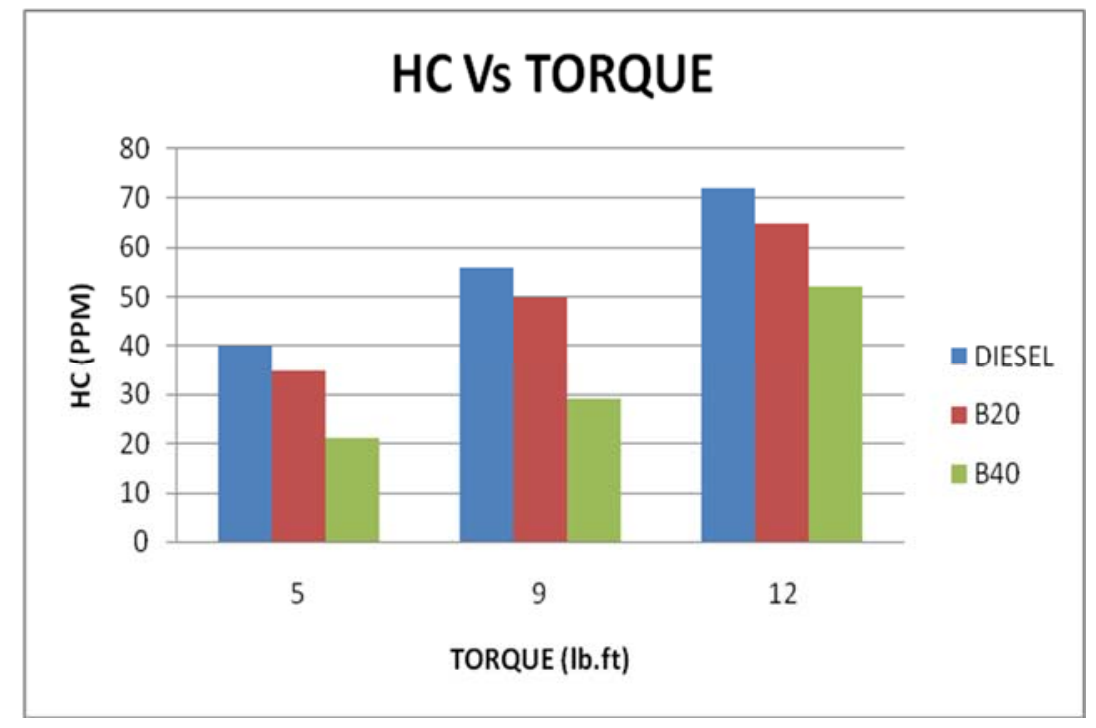

Figure 2: $\mathrm{HC}$ vs Torque

The percentage $\mathrm{HC}$ for diesel was recorded more than B20 at different loads while B20 was recorded to have more $\mathrm{HC}$ than B40. For $5 \mathrm{lb}$.ft Torque, the HC count for B40. While that of B20 blend was a bit higher, diesel had the highest $\mathrm{HC}$ count at this load condition. Similarly, diesel remain the one with highest HC count when engine was running at the torque values of 9 and $12 \mathrm{lb} . \mathrm{ft}$, followed by B20 and B40 having the least $\mathrm{HC}$ count.

Similar trend was recorded in the emissions of carbon monoxide $(\mathrm{CO})$ and carbon dioxide $\left(\mathrm{CO}_{2}\right)$ as well. The trends are shown graphically in figure 3 and 4 . 


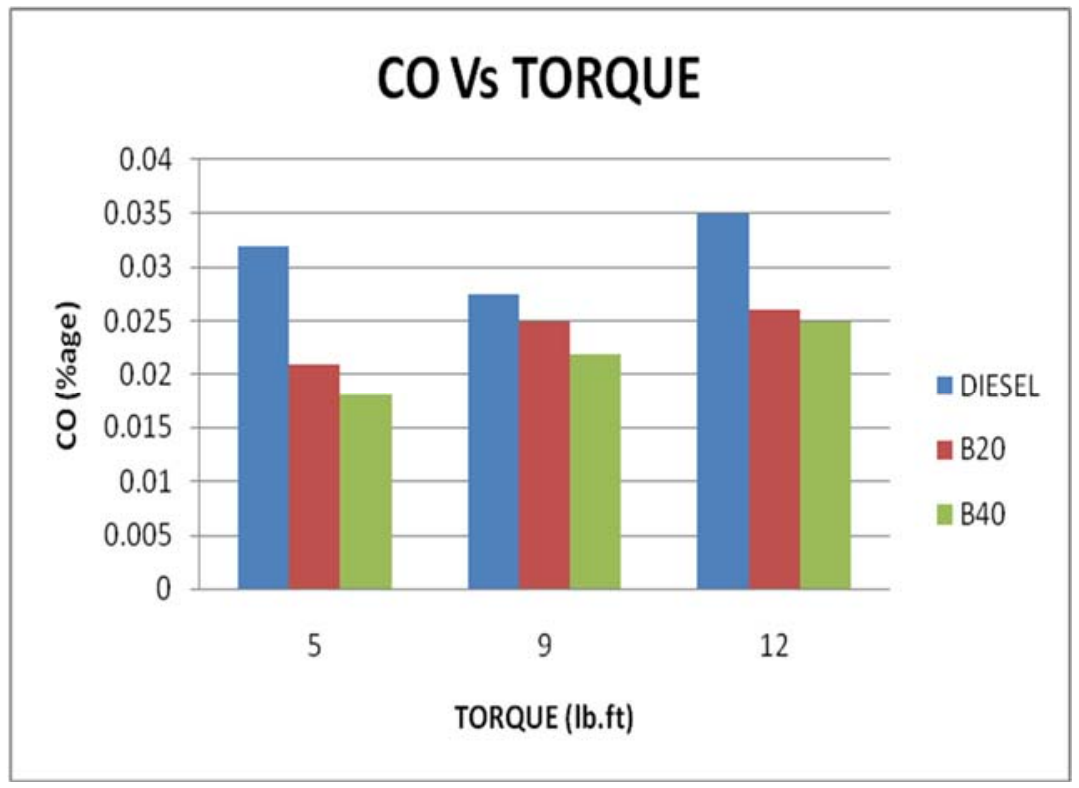

Figure 3: CO vs Torque

The quantity of both carbon monoxide and dioxide in exhaust of engine increases as the load is increased for a fuel as shown in figure 3 and 4 , also as the blending of biodiesel increases the carbon dioxide percentage decreases. For every value of torque, B40 blend of Jatropha biodiesel has the lowest $\mathrm{CO}_{2}$ emission percentage, while those of conventional diesel has the highest $\mathrm{CO}_{2}$ emission percentage.

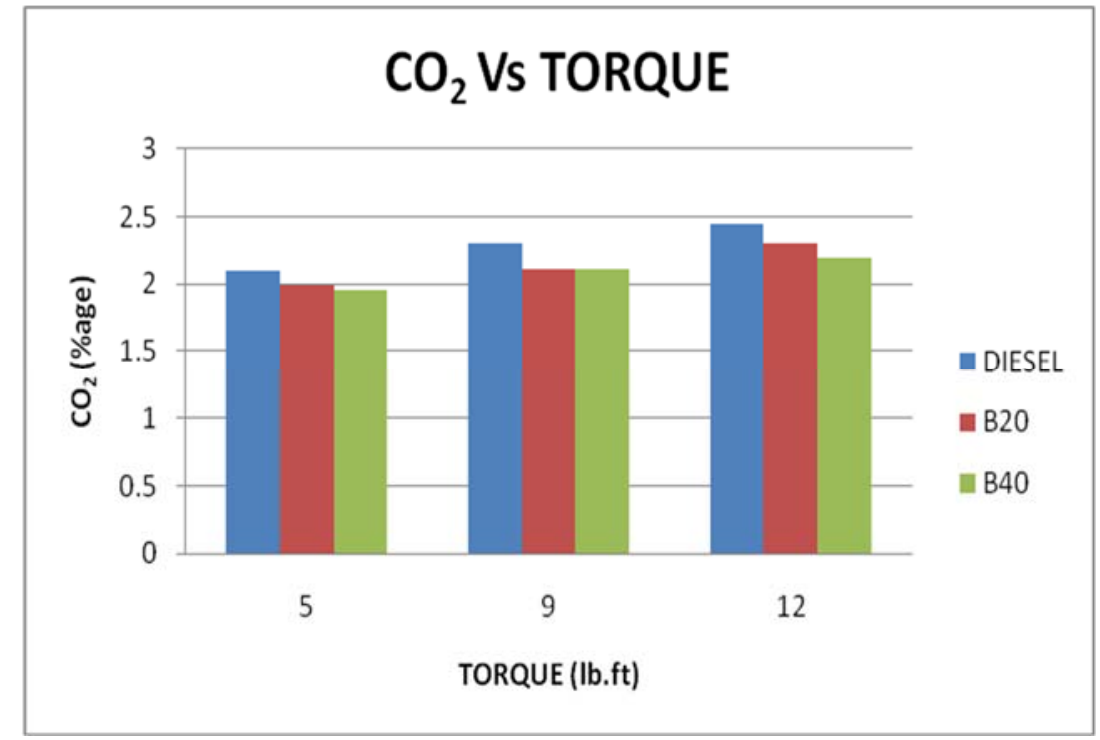

Figure 4: $\mathrm{CO}_{2}$ vs Torque

\section{a. Engine Performance}

Figure 5 shows the relation between horsepower and efficiency of the three fuels used in our experiments i.e. Diesel, B20 and B40, the efficiency of B20 blend is more than B40 blend, it is much closer to the efficiency curve of conventional diesel. However, it can be observed from the figure that diesel, biodiesel and its blends follow similar trend, but mechanical efficiencies decrease with the increase of biodiesel percentages in the blends. 


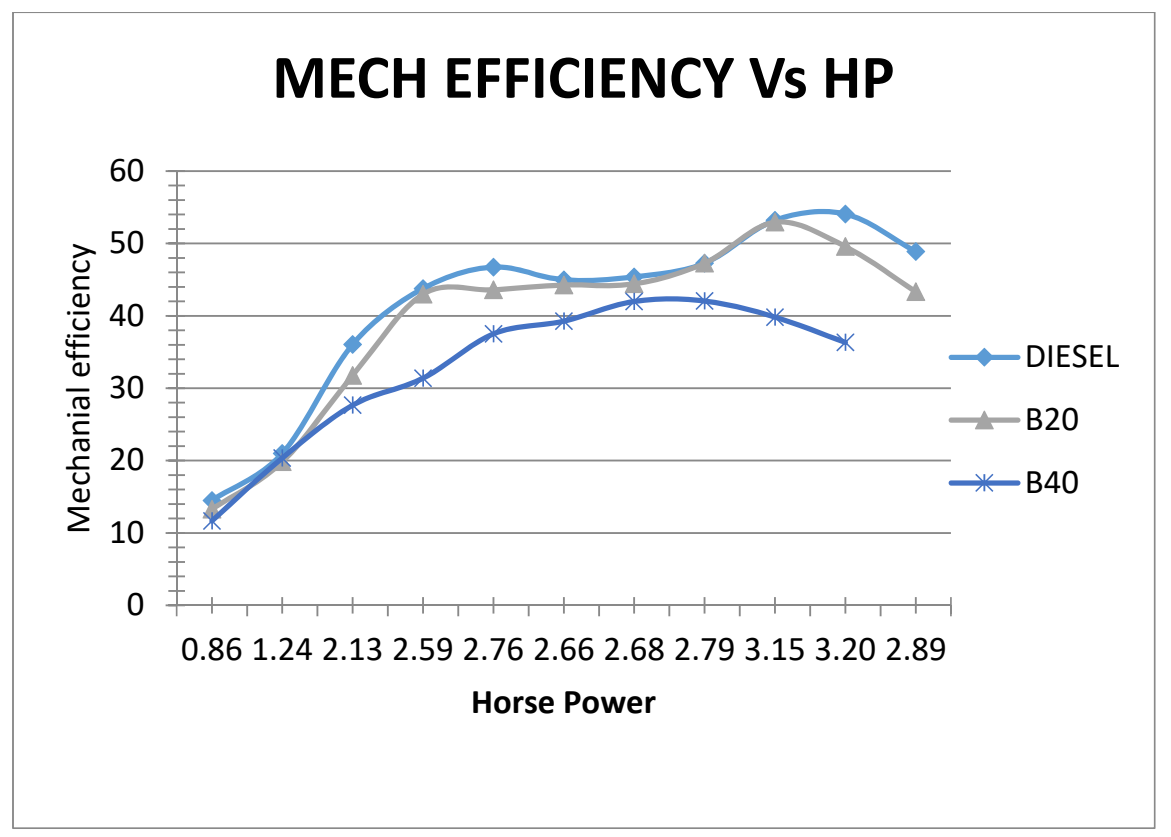

Figure 5: Mechanical Efficiency vs. Horsepower of Diesel, B20 and B40 blends of Biodiesel

The decrease of mechanical efficiency with increase of biodiesel percentage may arise from its combustion characteristics having relatively high flash point, high viscosity and low volatility.

\section{CONCLUSIONS}

Jatropha curcas L oil is gaining popularity among many researchers as the raw material for Biodiesel production because it is nonedible due to presence of toxic compounds, high in oil content and properties similar to conventional diesel. The investigation was carried out to measure and compare the performance and exhaust emissions of Jatropha biodiesel of 2 different blends i.e. B20 and B40 against the conventional diesel fuel in a fully instrumented, 4-stroke $10 \mathrm{hp} \mathrm{diesel} \mathrm{engine.}$

It is noted that, there is a considerable amount of $\mathrm{CO}$ and $\mathrm{HC}$ emissions reduction when blends of biodiesel are used as fuel. The present investigation concludes that from performance and emission, B20 can be used as alternative fuel blend for conventional diesel fuel.

Theoretically, the characteristics of diesel engine combustion coupled with the physiochemical properties of biodiesel against those of conventional diesel provide us sound basis to support the correct interpretation of the observed engine behavior.

\section{REFERENCES}

[1] Shafiee, S. and E. Topal, When will fossil fuel reserves be diminished? Energy policy, 2009. 37(1): p. 181-189.

[2] Koh, M.Y. and T.I.M. Ghazi, A review of biodiesel production from Jatropha curcas L. oil. Renewable and Sustainable Energy Reviews, 2011. 15(5): p. 2240-2251.

[3] Nalgundwar, A., B. Paul, and S.K. Sharma, Comparison of performance and emissions characteristics of DI CI engine fueled with dual biodiesel blends of palm and jatropha. Fuel, 2016. 173: p. 172-179.

[4] Srivastava, A. and R. Prasad, Triglycerides-based diesel fuels. Renewable and sustainable energy reviews, 2000. 4(2): p. 111-133.

[5] Krawczyk, T., Biodiesel-alternative fuel makes inroads but hurdles remain. inform, 1996. 7: p. 801-815.

[6] Abedin, M., et al., Performance, emissions, and heat losses of palm and jatropha biodiesel blends in a diesel engine. Industrial crops and products, 2014. 59: p. 96-104.

[7] Rodrigues, J., et al., Biodiesel production from crude Jatropha oil catalyzed by non-commercial immobilized heterologous Rhizopus oryzae and Carica papaya lipases. Bioresource technology, 2016. 213: p. 88-95.

[8] de Oliveira, J.S., et al., Characteristics and composition of Jatropha gossypiifoliaand Jatropha curcas L. oils and application for biodiesel production. Biomass and Bioenergy, 2009. 33(3): p. 449-453.

[9] Alptekin, E. and M. Canakci, Determination of the density and the viscosities of biodiesel-diesel fuel blends. Renewable energy, 2008. 33(12): p. 2623-2630.

[10] Chauhan, B.S., N. Kumar, and H.M. Cho, A study on the performance and emission of a diesel engine fueled with Jatropha biodiesel oil and its blends. Energy, 2012. 37(1): p. 616-622. 